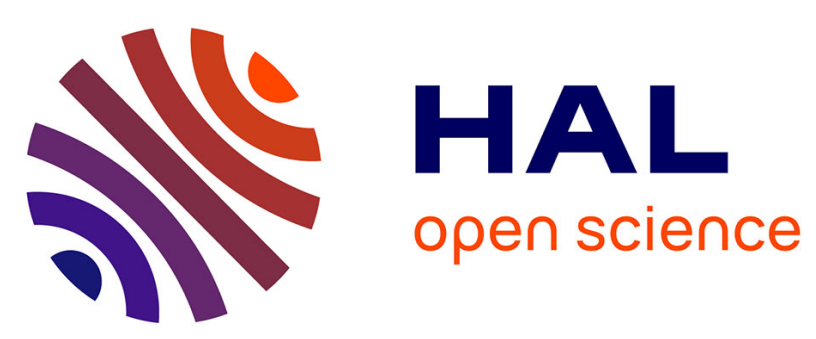

\title{
A coupled model for carbon and radiocarbon evolution during the last deglaciation
}

Véronique Mariotti, Didier Paillard, Laurent Bopp, Didier M. Roche, Nathaëlle Bouttes

\section{- To cite this version:}

Véronique Mariotti, Didier Paillard, Laurent Bopp, Didier M. Roche, Nathaëlle Bouttes. A coupled model for carbon and radiocarbon evolution during the last deglaciation. Geophysical Research Letters, 2016, 43 (3), pp.1306-1313. 10.1002/2015GL067489 . hal-01587469

\author{
HAL Id: hal-01587469 \\ https://hal.science/hal-01587469
}

Submitted on 18 Dec 2020

HAL is a multi-disciplinary open access archive for the deposit and dissemination of scientific research documents, whether they are published or not. The documents may come from teaching and research institutions in France or abroad, or from public or private research centers.
L'archive ouverte pluridisciplinaire HAL, est destinée au dépôt et à la diffusion de documents scientifiques de niveau recherche, publiés ou non, émanant des établissements d'enseignement et de recherche français ou étrangers, des laboratoires publics ou privés. 


\section{Geophysical Research Letters}

\section{RESEARCH LETTER}

10.1002/2015GL067489

Key Points:

- Explaining the deglacial evolution of carbon and radiocarbon in the ocean and in the atmosphere

- Providing a fully consistent framework through the use of a coupled carbonclimate model

- The first simulation of ${ }^{14} \mathrm{C}$ reservoir ages during the deglaciation

Supporting Information:

- Texts S1 and S2 and Figures S1-S4

- Figure S1

- Figure S2

- Figure S3

- Figure S4

- Data Set S1

- Data Set S2

- Data Set S3

- Data Set S4

- Data Set S5

Correspondence to:

D. Paillard,

Didier.Paillard@lsce.ipsl.fr

Citation:

Mariotti, V., D. Paillard, L. Bopp, D. M. Roche, and N. Bouttes (2016), A coupled model for carbon and radiocarbon evolution during the last deglaciation, Geophys. Res. Lett., 43, 1306-1313, doi:10.1002/ 2015 GL067489.

Received 17 DEC 2015 Accepted 21 JAN 2016 Accepted article online 25 JAN 2016 Published online 13 FEB 2016

\section{A coupled model for carbon and radiocarbon evolution during the last deglaciation}

\author{
Véronique Mariotti ${ }^{1}$, Didier Paillard ${ }^{1}$, Laurent Bopp ${ }^{1}$, Didier M. Roche ${ }^{1,2}$, and Nathaëlle Bouttes ${ }^{3}$ \\ ${ }^{1}$ Laboratoire des Sciences du Climat et de I'Environnement, IPSL-CEA-CNRS-UVSQ, UMR 8212, Centre d'Etudes de Saclay, Gif \\ Sur Yvette, France, ${ }^{2}$ Cluster Earth and Climate, Faculty of Earth and Life Sciences, Vrije Universiteit Amsterdam, Amsterdam, \\ Netherlands, ${ }^{3}$ NCAS-Climate, Department of Meteorology, University of Reading, Reading, UK
}

Abstract Changes in the ventilation of the Southern Ocean are thought to play an important role on deglacial carbon and radiocarbon evolution but have not been tested within a coupled climate-carbon model. Here we present such a simulation based on a simple scenario of transient deglacial sinking of brines —sea ice salt rejections-around Antarctica, which modulates Southern Ocean ventilation. This experiment is able to reproduce deglacial atmospheric changes in carbon and radiocarbon and also ocean radiocarbon records measured in the Atlantic, Southern, and Pacific Oceans. Simulated for the first time in a fully coupled climate-carbon model of intermediate complexity including radiocarbon, our modeling results suggest that the deglacial changes in atmospheric carbon dioxide and radiocarbon were achieved by means of a breakdown in the glacial brine-induced stratification of the Southern Ocean.

\section{Introduction}

During the last deglaciation, the atmospheric carbon dioxide $\left(\mathrm{pCO}_{2}\right)$ increased from around 190 parts per million by volume (ppmv) at the Last Glacial Maximum (LGM; 21,000-18,000 years ago) to 265-270 ppmv at the beginning of the Holocene [Monnin et al., 2001; Marcott et al., 2014] ( 9000 years ago). In the meantime, the atmospheric radiocarbon activity $\left(\Delta^{14} C_{\text {atm }}\right)$ decreased from around 450 to 75 per mil (\%o) [Reimer et al., 2013]. Of particular interest are the simultaneous two-step changes in both concentrations, with a first $p \mathrm{CO}_{2}$ rise and $\Delta^{14} \mathrm{C}_{\text {atm }}$ decrease during the so-called "Mystery Interval" ( 18,000-14,600 years ago), and a second $p \mathrm{CO}_{2}$ rise [Monnin et al., 2001] and $\Delta^{14} C_{\text {atm }}$ decrease between 12,800 and 9000 years ago, and the simultaneous plateau in between during the Antarctic Cold Reversal (ACR; 14,600-12,800 years ago) with constant concentrations of $p \mathrm{CO}_{2}$ (240 ppmv) and $\Delta^{14} \mathrm{C}_{\mathrm{atm}}(\sim 200 \%)$ ). $\Delta^{14} \mathrm{C}_{\mathrm{atm}}$ variations depend on cosmogenic production and carbon cycling. Geomagnetic field and ${ }^{10} \mathrm{Be}$-based reconstructions have shown that radiocarbon production alone cannot explain the deglacial decrease in $\Delta^{14} C_{a t m}$ [Muscheler et al., 2004]. In parallel, ice core and marine record data suggest that most of the $\mathrm{pCO}_{2}$ increase is driven by marine processes in the Southern Ocean during the last deglaciation [Monnin et al., 2001; Barker et al., 2009], while Northern Hemisphere processes might have an important role to account for more rapid events [Marcott et al., 2014; Chen et al., 2015]. One of the leading hypotheses to explain both $p \mathrm{CO}_{2}$ and $\Delta^{14} \mathrm{C}_{\mathrm{atm}}$ deglacial changes is the outgassing of a radiocarbon-depleted and carbon-enriched deep ocean reservoir from the Southern Ocean. This hypothesis has been supported by recent measurements on foraminifera [Skinner et al., 2010] and on deep-sea corals [Burke and Robinson, 2012]. Nonetheless, the simultaneous deglacial $p \mathrm{CO}_{2}$ and $\Delta^{14} C_{\mathrm{atm}}$ have never been simulated with fully coupled climate-carbon models.

Brine-induced changes of the glacial ocean have been proposed to explain $\mathrm{LGM}_{\mathrm{CCO}}$ [Paillard and Parrenin, 2004; Bouttes et al., 2010, 2011] and $\Delta^{14} C_{\text {atm }}$ concentrations [Mariotti et al., 2013]. When sea ice forms, it releases pockets of cold and very salty water, called "brines", that sink underneath and are mixed through the water column. When this phenomenon takes place over the continental shelf around Antarctica, these salty waters can accumulate over the shelf without significant mixing with the open ocean subsurface waters [e.g., Ohshima et al., 2013]. These very dense waters can then flow along the topography and participate in the formation of Antarctic bottom waters. Such dense shelf water masses are measured nowadays in the Weddell Sea, with water plumes reaching depths greater than $2000 \mathrm{~m}$ on the continental slope without much mixing with the surrounding water masses, since the downflow becomes supercritical [Foldvik et al., 2004]. Recent measurements have clearly demonstrated the same phenomenon at Cape Darnley [Ohshima et al., 2013] where these brine-sinking waters contribute today to Antarctic bottom waters (AABW) for about 
1.5 Sv (sverdrup, $1 \mathrm{~Sv}=10^{6} \mathrm{~m}^{3} \mathrm{~s}^{-1}$ ). Under cold glacial conditions, these brine-sinking processes are likely to be more important and the transport of salt toward the bottom ocean should be higher. Indeed, sea ice production around Antarctica is likely to be enhanced, while melting of the Antarctic ice sheet, in particular, basal melting under ice platforms, should be significantly reduced whereas it is today an important source of freshwater [Kusahara et al., 2011]. Therefore, the salinity of shelf waters should increase as well as the amount of dense salty shelf water overflowing the continental slope to reach the abyssal ocean. This dense and salty AABW formation increases the global vertical ocean stratification, in particular, in the Southern Ocean as evidenced by LGM pore water measurements [Adkins et al., 2002], and the concomitant downward accumulation of carbon builds up an isolated deep ocean carbon reservoir.

\section{Methods}

\subsection{Coupled Carbon-Climate Model}

We use the model of intermediate complexity CLIMBER-2 (CLIMate-BiosphERe model) [Petoukhov et al., 2000]. This is a fully coupled carbon-climate model, with a two-dimensional (vertically averaged) statistical dynamical atmospheric model, a 2.5-dimensional dynamics/thermodynamics ocean model that includes ocean carbon cycling and a dynamics/thermodynamics sea ice model, and a terrestrial vegetation model (with three types of surface: tree, grass, and bare soil). The ocean model has 20 vertical levels and simulates the zonally averaged temperature, salinity, and meridional and vertical velocities for three individual ocean basins (Atlantic, Pacific, and Indian). The ocean carbon model includes a sediment module that represents the carbonate compensation process and computes explicitly the radiocarbon isotope [Brovkin et al., 2007, 2002]. The model has been successfully tested under present [Petoukhov et al., 2000] and glacial [Ganopolski and Rahmstorf, 2001] climate conditions. A transient simulation of the deglaciation with the fully coupled carbon-climate model was already presented in Bouttes et al. [2012a] with a detailed presentation of the brine-sinking mechanism. For the specific needs of our study, we have further developed this model: $\Delta^{14} \mathrm{C}_{\mathrm{atm}}$ is interactively computed by the model with explicit exchanges with the ocean, the terrestrial biosphere and with a prescribed cosmogenic source [Mariotti et al., 2013].

\subsection{External Forcings and Parameterization of the Simulation}

The simulations presented here and in the supporting information are all forced with documented deglacial solar insolation [Berger, 1978], ice sheets [Peltier, 2004], and cosmogenic radiocarbon production changes obtained from paleomagnetic intensity [Laj et al., 2002]. The absolute value of the production rate was tuned to reproduce the present-day ${ }^{14} \mathrm{C}$ distribution [Mariotti et al., 2013], resulting in a production rate of 1.75 atom $\mathrm{cm}^{-2} \mathrm{~s}^{-1}$, in very good agreement with recent estimates (for instance, 1.64 and 1.88 atom cm $\mathrm{cm}^{-2} \mathrm{~s}^{-1}$ for, respectively, the present time and for the preindustrial epoch according to Kovaltsov et al. [2012]). Our scaling of the paleomagnetic reconstruction is in close agreement with more sophisticated production models [see Hain et al., 2014], as illustrated by Figure 1a.

The carbon cycle model is fully coupled to the climate model, which means that the $p \mathrm{CO}_{2}$ calculated in the carbon cycle model is used in the radiative code of the climate model. The sinking of brines mechanism is represented by the "frac" parameter [Bouttes et al., 2010, 2012a] that corresponds to the fraction of salt released by sea ice formation that ultimately sinks to the bottom of the ocean. This represents the efficiency of topographic density currents to transport salt downward. The frac parameter varies between 0 and 1, which corresponds respectively to brines being entirely released either at the ocean surface or at the ocean bottom. When it is equal to 1, the resulting stratification effect is maximum (see supporting information for further details). It is possible to simulate the glacial-interglacial carbon transition through a decrease in the frac parameter, as a consequence of changes in Antarctica ice sheet extent [Bouttes et al., 2012a]. Here we are building our deglacial scenario for the sinking of brines (Figure 1b) on the opal flux time series of a Southern Ocean sediment core (Figure 1c), which is likely controlled by ventilation changes [Anderson et al., 2009] (Figure S1 of the supporting information). To generate the increased (respectively decreased) ventilation, the frac parameter is decreased (respectively increased). Particularly noteworthy is the period of the ACR: we set a resumption of the sinking of brines to reproduce the sea ice response to colder conditions around Antarctica [Parrenin et al., 2013] and the ventilation-driven decrease in Southern Ocean productivity. The simulation is also forced by a freshwater forcing of $0.3 \mathrm{~Sv}$ in the latitudes 50 to $70^{\circ} \mathrm{N}$ in the North Atlantic Ocean between 18 ka B.P. and 17 ka B.P., mimicking Heinrich event 1. In brief, our model is forced by variations 


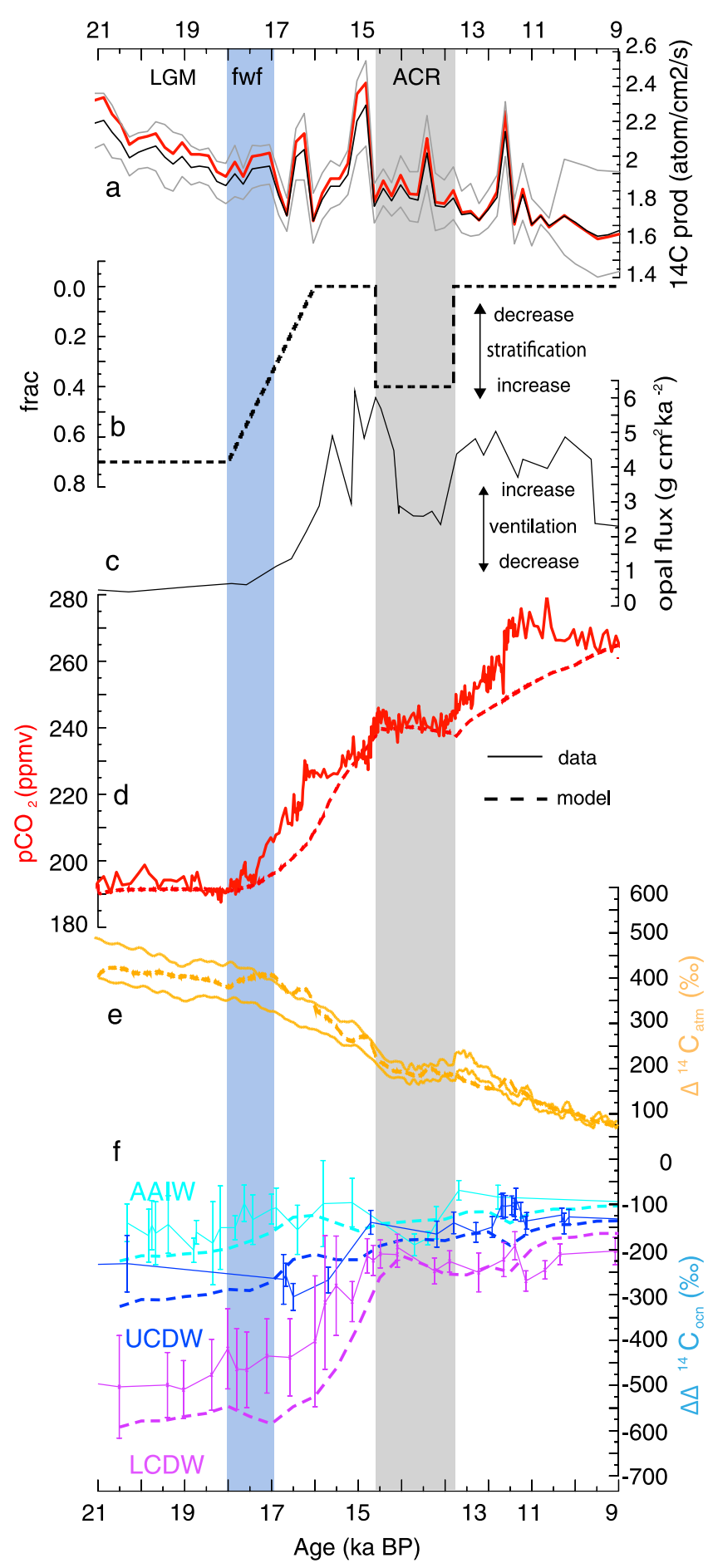

in insolation, ice sheet distribution, ${ }^{14} \mathrm{C}$ cosmogenic production, North Atlantic freshening, and Southern Ocean brine efficiency pathways.

It has been shown that ${ }^{14} \mathrm{C}$ production changes may have a long lasting influence on the overall ${ }^{14} \mathrm{C}$ cycle [Köhler et al., 2006], though it appears rather stable before the LGM, between $30 \mathrm{ka} \mathrm{B}$. P. and 20 ka B.P. [Hain et al., 2014]. Still, the deep ocean did experience important changes during this period associated with Heinrich and DansgaardOescher events, thereby possibly affecting the deep ${ }^{14} \mathrm{C}$ reservoirs. The state of ocean ${ }^{14} \mathrm{C}$ at LGM is therefore difficult to estimate. In the first coupled transient experiments presented here, we started our simulations from a LGM equilibrium state for climate, carbon, and ${ }^{14} \mathrm{C}$ similar to the one in Mariotti et al. [2013] (see supporting information).

Figure 1. Simulated deglacial $p \mathrm{CO}_{2}$ and $\Delta{ }^{14} \mathrm{C}$ (dashed lines) and data reconstructions (solid lines). (a) ${ }^{14} \mathrm{C}$ production used as forcing in the simulations (in red) (rescaled from Laj et al. [2002]) compared to the envelop (median, minimum, and maximum) from Hain et al. [2014]. (b) Scenario of sinking of brines represented by the parameter frac (section 2); (c) measured opal flux (in $\mathrm{g} \mathrm{cm}^{2}$ $\mathrm{ka}^{-1}$ ) from TN057-13PC [Anderson et al., 2009] as a proxy for ventilation in the Southern Ocean; (d) simulated (thick red dashes) and measured [Marcott et al., 2014] atmospheric $p \mathrm{CO}_{2}$ (in ppmv); (e) simulated $\Delta{ }^{14} C_{\text {atm }}$ (thick orange dashes) and reconstructed [Reimer et al., 2013] $\Delta{ }^{14} C_{\text {atm }}$ with 1 standard deviation envelope (orange thin line) (in \%o); (f) simulated (thick dashes) and measured (thin line with 2 sigma error bars) $\Delta \Delta^{14} C_{\text {ocn }}$ (in \%) of three water masses of the Southern Ocean (for clarity reasons, errors on data are represented here as simple error bars instead of tilted ellipses): AAIW (Antarctic Intermediate Water ( 300-800 $\mathrm{m}$ depth), in light blue) [de Pol-Holz et al., 2010; Burke and Robinson, 2012], UCDW (Upper Circumpolar Deep Water ( 600-1750 m depth) [Burke and Robinson, 2012], in dark blue), and LCDW (Lower Circumpolar Deep Water (3770 m depth) [Skinner et al., 2010], in purple) as function of time (in ka B.P., thousand years before present). The blue bar marks the time interval during which a freshwater flux (fwf) of $0.3 \mathrm{~Sv}$ was injected into the North Atlantic in order to mimick the Heinrich 1 event. Each record is plotted on its own respective time scale. 


\section{Results and Discussion}

In response to the changes of ocean circulation, the simulated atmospheric $p \mathrm{CO}_{2}$ and $\Delta^{14} \mathrm{C}$ are globally in agreement with data reconstructions (Figures $1 \mathrm{~d}$ and $1 \mathrm{e}$ ). More precisely, the drop of $\sim 190 \%$ in $\Delta^{14} \mathrm{C}$ and rise of $\sim 50$ ppm during the "Mystery Interval" are correctly represented. Of particular interest is the Antarctic Cold Reversal (ACR). The reinvigorated brine formation simulated during this period increases ocean stratification and carbon storage in the ocean. This results in a pause in the deglacial increase of $p \mathrm{CO}_{2}$ and decrease of $\Delta^{14} \mathrm{C}_{\mathrm{atm}}$ with $p \mathrm{CO}_{2}$ remaining stable at $\sim 240 \mathrm{ppm}$ and $\Delta \Delta^{14} \mathrm{C}_{\mathrm{atm}}$ at $\sim 190 \%$ o. During the two phases of the $p \mathrm{CO}_{2}$ increase, the model tends to simulate a slower rate of increase than in the ice core data (Figure 1d). The fact that our model simulates an increase in the terrestrial biospheric carbon reservoir during Heinrich event 1 (HE1) (Figure S2) contributes to this mismatch, which is also clearly visible in the $\delta^{13} C_{a t m}$ [Bouttes et al., 2012b]. Besides, high-resolution $\mathrm{pCO}_{2}$ data have recently revealed abrupt centennial increases [Marcott et al., 2014] coincident with Northern Hemisphere climatic abrupt warmings. Our scenarios were designed to reproduce the millennial trends in the deglaciation associated with deep ocean changes, and our model does not simulate this rapid centennial carbon variability, which might be linked to other processes [Köhler et al., 2014].

In the south, the decreased sinking of brines leads to an outgassing of $p \mathrm{CO}_{2}$ with a low ${ }^{14} \mathrm{C}$ signature through the Southern Ocean. In the north, the freshening induces upper water stratification that prevents the uptake of carbon by the ocean, thus maintaining rather high level of $\Delta^{14} \mathrm{C}_{\mathrm{atm}}$. Finally, the evolution of $p \mathrm{CO}_{2}$ and $\Delta^{14} \mathrm{C}_{\mathrm{atm}}$ are mostly explained by the sinking of brines scenario, while the contribution of the freshwater flux associated to HE1 is less significant for atmospheric concentrations.

Since the largest carbon pool is the ocean, it is critical to assess our model results against paleoceanographic data. Not only are the deglacial atmospheric $p \mathrm{CO}_{2}$ and $\Delta^{14} \mathrm{C}$ correctly represented, but the ocean $\Delta^{14} \mathrm{C}$ is also in general agreement with data in the North Atlantic, Southern, and Pacific Oceans, regions with clear signatures of intermediate, deep, and bottom water masses changes. The evolution of simulated water masses in the Southern Ocean reproduces well deglacial changes in ocean stratification reconstructed from data (Figure 1f). During the LGM, the three water masses AAIW (Antarctic Intermediate Water), UCDW (Upper Circumpolar Deep Water), and LCDW (Lower Circumpolar Deep Water) remain constant at three different levels of $\Delta \Delta^{14} \mathrm{C}_{\text {ocn }}$ (respectively $\sim-200,-300$, and $-575 \%$ ), reflecting the strong stratification in this region. $\Delta \Delta^{14} \mathrm{C}_{\text {ocn }}$ is defined as $\Delta \Delta^{14} \mathrm{C}_{\mathrm{ocn}}=\Delta^{14} \mathrm{C}_{\mathrm{ocn}}-\Delta^{14} \mathrm{C}_{\mathrm{atm}}$ consistently with data, though other past ocean radiocarbon definitions could also be appropriate [Cook and Keigwin, 2015]. Then, from 17 to 14 ka B.P., LCDW $\Delta \Delta^{14} C_{\text {ocn }}$ increases up to $-250 \%$, i.e., similar to the upper and intermediate water masses values, reflecting the increase in ventilation of Southern Ocean abyssal waters. In response to the reinvigorated sinking of brines during the $A C R$, the model simulates a small decrease of 50\%o in LCDW $\Delta \Delta^{14} C_{\text {ocn }}$ between 14 and 12.5 ka B.P. Finally, between 11.5 and 9 ka B.P., the three water masses have constant $\Delta \Delta^{14} C_{\text {ocn }}$ values that are close to each other, which show that the whole water column is well ventilated. The model seems to overestimate the sinking of brines mechanism and simulates LCDW $\Delta \Delta^{14} C_{\text {ocn }}$ that are slightly too low between 18 and $14.5 \mathrm{ka}$ B.P. compared to the single record available [Skinner et al., 2010].

The simulated North Atlantic and Pacific water masses are also in agreement, respectively, with marine records from the North West Atlantic Ocean ( $\left.36^{\circ} \mathrm{N}\right)$ [Robinson et al., 2005] and from the Pacific [de la Fuente et al., 2015] (Figure 2). During the LGM, the ocean remains well stratified, as can be seen from the horizontal isolines of $\Delta \Delta^{14} \mathrm{C}_{\text {ocn }}$. Between 18 and $14.6 \mathrm{ka} \mathrm{B} / \mathrm{P} /$, there is a two-step change in $\Delta \Delta^{14} \mathrm{C}_{\text {ocn }}$ in the Atlantic in response to both sinking of brines and freshwater forcing scenarios: between 18 and $17 \mathrm{ka}$ B.P., the ocean becomes even more stratified than the glacial ocean, especially in the upper part (above $2000 \mathrm{~m}$ ) because of the shutdown of the Atlantic Meridional Overturning Circulation (AMOC) in response to the freshening scenario. Then, the ventilation of the ocean increases to reach the whole water column in response to both the reduced sinking of brines and the reinvigorated AMOC after the cessation of the freshening. In the Pacific, this transition is smoother and we do not see any clear imprint of the HE1 freshwater input. Between 14.6 and 12.8 ka B.P., there is a short resumption of a ${ }^{14} \mathrm{C}$-depleted deep ocean reservoir below $3000 \mathrm{~m}$ due to the reinvigorated sinking of brines during the ACR visible in the Atlantic basin but more diffuse in the Pacific. This water mass progressively disappears between 12.8 and 9 ka B.P. due to the simulated shutdown of the sinking of brines. Again, the model simulates abyssal $\Delta \Delta^{14} \mathrm{C}_{\text {ocn }}$ water mass values during the $L G M$ that are too low. It reproduces well the transition of $\Delta \Delta^{14} \mathrm{C}_{\text {ocn }}$ at $15.5 \mathrm{ka}$ B.P. between 1000 and $2500 \mathrm{~m}$ documented by $\sim 20$ records in the Atlantic, as well as in 

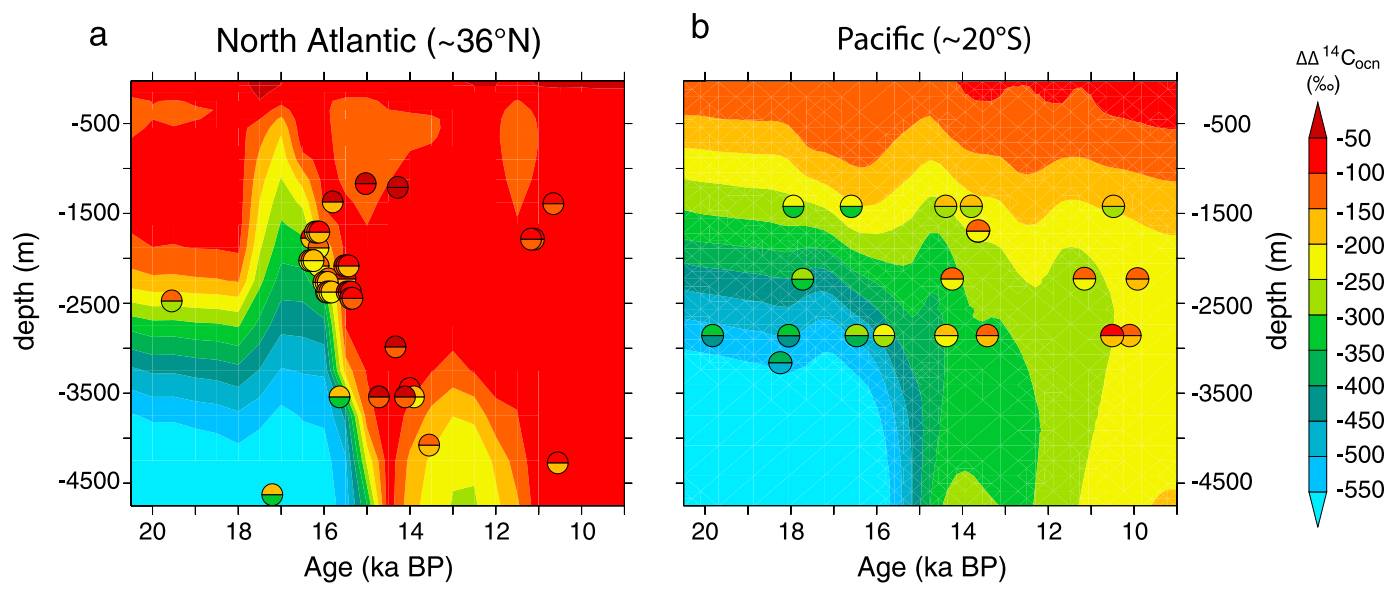

Figure 2. Simulated $\Delta \Delta^{14} \mathrm{C}_{\mathrm{ocn}}$ and reconstructed $\Delta \Delta^{14} \mathrm{C}_{\mathrm{ocn}}$ in the (left) North West Atlantic Ocean $\left(\sim 36^{\circ} \mathrm{N}\right)$ and the (right) South Tropical Pacific $\left(\sim 20^{\circ} \mathrm{S}\right)$. The filled background is the model output whereas the data points are from Robinson et al. [2005] using measurements on both corals (32 points) and foraminifera (13 points) in the Atlantic and from the compilation in de la Fuente et al. [2015] in the Equatorial East Pacific $\left(\sim 6^{\circ} \mathrm{S}\right)$ and the SW Pacific $\left(\sim 40^{\circ} \mathrm{S}\right)$. The upper (respectively lower) part of the circles represents the maximum (respectively minimum) value of $\Delta \Delta^{14} \mathrm{C}_{\mathrm{ocn}}$ in the data.

the Pacific where this transition has a larger amplitude in the deep levels (at about $3000 \mathrm{~m}$ depth) than in the intermediate ones ( 1500 m). As in several other ${ }^{14} \mathrm{C}$ ocean models [Orr, 2004; Tschumi et al., 2011], the absolute ${ }^{14} \mathrm{C}$ values in the deep Pacific ocean are too negative by 50 to $100 \%$ consistently with the control present-day run [see Mariotti et al., 2013].

Overall, concerning the glacial to interglacial changes, our results are broadly consistent with previous geochemical box model studies [e.g., Köhler et al., 2006; Hain et al., 2014] which have demonstrated the critical role of the Southern Ocean on atmospheric $p \mathrm{CO}_{2}$ and more generally the impact of deep ocean changes on $\Delta \Delta^{14} C_{\text {atm }}$. When examining more closely the transient events, the brine-sinking scenario explains $\sim 75 \%$ of the first rise in $p \mathrm{CO}_{2}$ (18 to $14.6 \mathrm{ka}$ B.P.) in our simulation, while the freshening scenario accounts only for $~ 25 \%$ of it (Figure 3). The role of brine sinking on the evolution of $\Delta^{14} C_{\text {atm }}$ is even more important since, together with the ${ }^{14} \mathrm{C}$ production changes, it explains most of the simulated changes, while the freshening scenario only has a much smaller impact (Figure 3). More precisely, the consequence of the freshwater flux (fwf) is to store carbon in the deep Atlantic thus older deep-ocean ${ }^{14} \mathrm{C}$ and slightly younger atmospheric ${ }^{14} \mathrm{C}$, without much impact on $p \mathrm{CO}_{2}$. It is only when brine-sinking stops at $16 \mathrm{ka}$ B.P. that this carbon can be released in the atmosphere therefore a slightly larger $p \mathrm{CO}_{2}(+10 \mathrm{ppm})$ in this simulation during a few millennia. This is rather different in Hain et al. [2014] where Northern Hemisphere freshwater discharges had an important impact on transient $\Delta \Delta^{14} C_{\text {atm }}$ excursions, but with the side effects of producing sharp increases in $\Delta{ }^{14} C_{a t m}$ associated to abrupt North Atlantic Deep Water resumptions. They consequently suggested adding an unexplained "thermocline thickening" mechanism to counterbalance this feature. In our simulations, the carbon cycle evolution and $\Delta^{14} C_{\text {atm }}$ are controlled primarily by the size of the deep carbon reservoir and less by the Atlantic reservoir, thus a smoother response of $\Delta{ }^{14} C_{\text {atm }}$ to freshwater forcing in the north.

Based on the model-data comparison, this study supports the hypothesis of an isolated deep glacial carbon ocean reservoir and gives a physical mechanism within a coherent climate background to explain the $190 \%$ drop in $\Delta^{14} C_{\text {atm }}$ during the so-called Mystery Interval. Together with previous simulations and model-data comparison of marine benthic ${ }^{13} \mathrm{C}$ over this period [Bouttes et al., 2010, 2012a], our results suggest that brine sinking is a key mechanism to explain not only present-day AABW formation [Ohshima et al., 2013] but also its variations through the last deglaciation. Because our study tends to demonstrate the leading role of a small and regional-scale mechanism such as the sinking of brines in explaining large-scale variations in climate and $p \mathrm{CO}_{2}$, it calls for models resolving more explicitly processes occurring over the Antarctic continental shelves, something still out of reach of current global climate models. The time evolution of the brine-sinking scenario was here based on observations. In future studies, it should be based on a detailed evolution of the ice sheet [e.g., The Reconstruction of Antarctic Ice Sheet Deglaciation Consortium et al., 2014] and its interaction with 


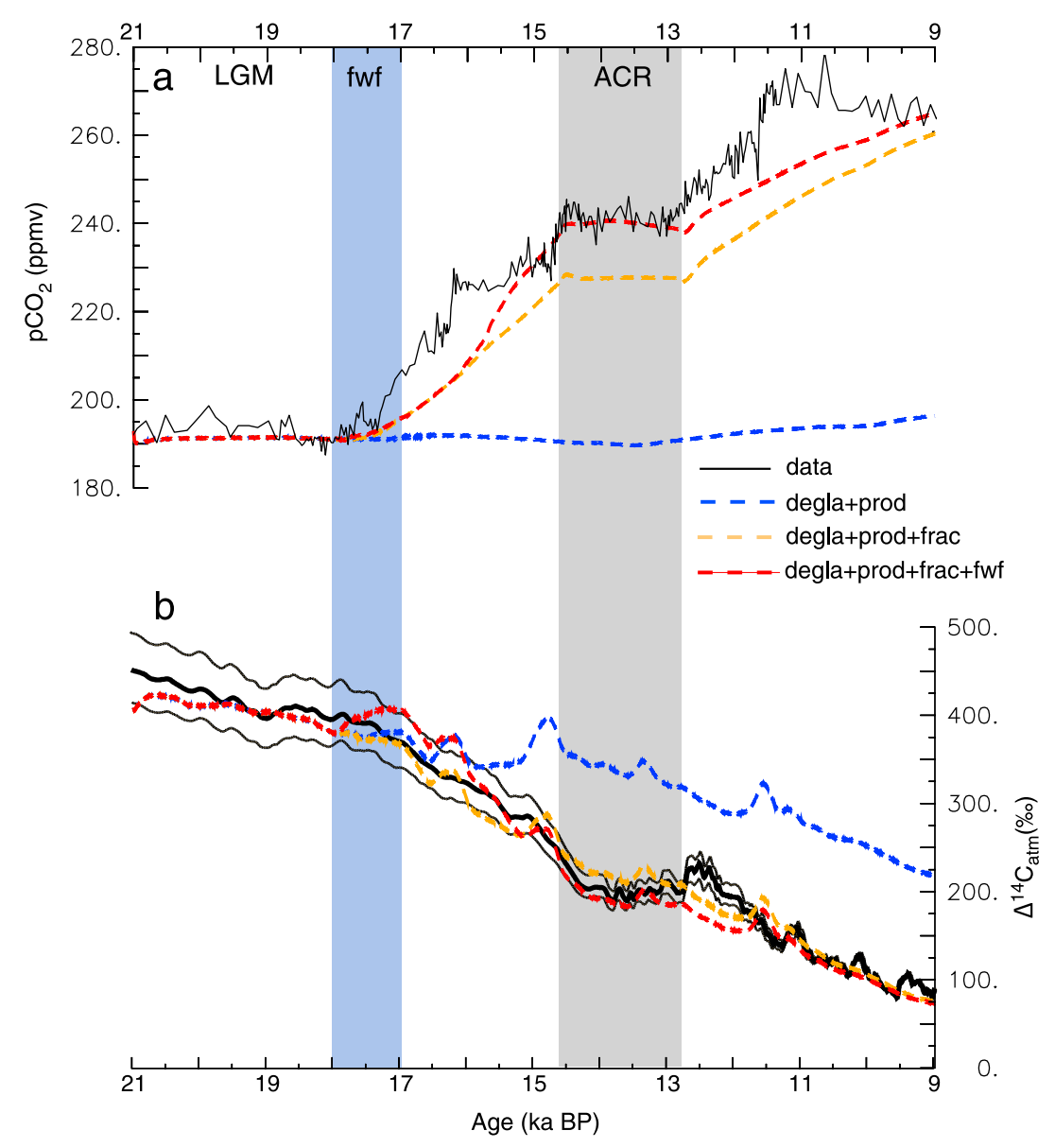

Figure 3. The relative roles of sinking of brines, Heinrich event 1 freshening and reconstructed cosmogenic production on $p \mathrm{CO}_{2}$ and $\Delta{ }^{14} \mathrm{C}_{\mathrm{atm}}$. Simulated (thick dashed lines) (a) $p \mathrm{CO}_{2}$; (b) $\Delta \Delta^{14} \mathrm{C}_{\mathrm{atm}}$ compared to data reconstructions (black line). Three simulations are plotted. In blue (degla + prod) a LGM-fixed sinking of brines scenario with the prescribed cosmogenic ${ }^{14} \mathrm{C}$-production rate [Laj et al., 2002]. In orange (degla + prod + frac) the changing deglacial sinking of brines scenario with the prescribed cosmogenic ${ }^{14} \mathrm{C}$-production rate. In red (degla + prod + frac + fwf) same as the precedent but with the Heinrich event 1 freshening scenario (i.e., simulation of Figure 1). Note that all simulations are forced by the melting of Northern Hemisphere ice sheets as well as the astronomical changes ("degla"). We compared the simulations to $p \mathrm{CO}_{2}$ [Marcott et al., 2014] and $\Delta{ }^{14} C_{\text {atm }}$ reconstructions [Reimer et al., 2013] (with 1 sigma uncertainties thin black lines).

Antarctic dense shelf waters [Kusahara et al., 2011]. Based on our results, it appears that a glacial cosmogenic production rate higher than what has been reconstructed (i.e., 1.2 to 1.4 times the present-day rate) is not necessary to explain deglacial changes in $\Delta^{14} C_{\text {atm}}$, since changes in ocean circulation are sufficient.

This study also points out that ocean circulation changes can induce nonnegligible variations in surface reservoir ages (Figures S3 and S4). This finding was already noted in the INTCAL13 project [Reimer et al., 2013] and in previous modeling studies [Singarayer et al., 2008; Ritz et al., 2008; Butzin et al., 2012]. These model results exemplify the large advantage of using a fully coherent and dynamical carbon cycle both in the atmosphere and in the ocean, both forced solely by a physical coupled model, since this strategy can also provide consistent estimates of transient surface reservoir ages. The next step is to perform a comparable simulation using a 3-D ocean model, in order to obtain the geographically resolved information that could be useful for better ${ }^{14} \mathrm{C}$ age estimations.

\section{Conclusion}

In conclusion, this paper proposes a first-order physical mechanism to explain both the deglacial changes in $p \mathrm{CO}_{2}$ and $\Delta^{14} \mathrm{C}$ due to changes in brine-sinking efficiency. This mechanism supports the hypothesis of an abyssal old carbon reservoir outgassed through the Southern Ocean to explain the Mystery Interval as 
suggested by previous carbon cycle box model studies, where the ocean circulation is imposed a priori [e.g., Hain et al., 2014]. Here we are providing a more physically based view with the use of a coupled climatecarbon model, which allows to test directly the impact of brine-sinking and freshwater scenarios on ocean dynamics and carbon cycle. Earlier studies [Bouttes et al., 2012a, 2012b] have also demonstrated that this mechanism explains well the deglacial history of benthic ${ }^{13} \mathrm{C}$ isotopes in the ocean, so our physically based scenario appears consistent with most carbon isotopic data available so far.

\section{Acknowledgments}

We are grateful to two anonymous reviewers for their thoughtful reviews. We thank Valérie Masson-Delmotte, Myriam Guillevic, and Claire Waelbroeck for comments on the atmospheric and oceanic reconstructions. V.M. and D.P. were supported by the French Alternative Energies and Atomic Energy Commission funding L.B. and D.M.R. were supported by the French National Center for Scientific Research funding. N.B. was funded by the European Research Council under the European Community's Seventh Framework Programme (FP7/2007-2013), ERC grant agreement 247220, project "Seachange." The model results shown on Figures S1, S2, S3, and S4 are available as supporting information and also at https:// doi.org/10.1594/PANGAEA.856973.

\section{References}

Adkins, J. F., K. McIntyre, and D. P. Schrag (2002), The salinity, temperature and $\delta^{18} \mathrm{O}$ of the glacial deep ocean, Science, 298, 1769-1773. Anderson, R., S. Ali, L. Bradtmiller, S. Nielsen, M. Fleisher, B. Anderson, and L. Burckle (2009), Wind-driven upwelling in the Southern Ocean and the deglacial rise in atmospheric $\mathrm{CO}_{2}$, Science, 323(5920), 1443-1448, doi:10.1126/science.1167441.

Barker, S., P. Diz, M. J. Vautravers, J. Pike, G. Knorr, I. R. Hall, and W. S. Broecker (2009), Interhemispheric Atlantic seesaw response during the last deglaciation, Nature, 457(7233), 1097-1102, doi:10.1038/nature07770.

Berger, A. (1978), Long-term variations of daily insolation and quaternary climatic changes, J. Atmos. Sci, 35, 2362-2367, doi:10.1175/ 1520-0469(1978)035<2362:LTVODI>2.0.CO;2.

Bouttes, N., D. Paillard, and D. Roche (2010), Impact of brine-induced stratification on the glacial carbon cycle, Clim. Past, 6(5), doi:10.5194/cp-6-575-2010.

Bouttes, N., D. Paillard, D. Roche, V. Brovkin, and L. Bopp (2011), Last glacial maximum $\mathrm{CO}_{2}$ and $\delta{ }^{13} \mathrm{C}$ successfully reconciled, Geophys. Res. Lett., 38, L02705, doi:10.1029/2010GL044499.

Bouttes, N., D. Paillard, D. M. Roche, C. Waelbroeck, M. Kageyama, A. Lourantou, E. Michel, and L. Bopp (2012a), Impact of oceanic processes on the carbon cycle during the last termination, Clim. Past, 8(1), 149-170.

Bouttes, N., D. Paillard, and D. M. Roche (2012b), Systematic study of the impact of fresh water fluxes on the glacial carbon cycle, Clim. Past, $8(2), 589-607$

Brovkin, V., J. Bendtsen, M. Claussen, A. Ganopolski, C. Kubatzki, V. Petoukhov, and A. Andreev (2002), Carbon cycle, vegetation, and climate dynamics in the holocene: Experiments with the CLIMBER-2 model, Global Biogeochem. Cycles, 16(4), 1139, doi:10.1029/2001GB001662.

Brovkin, V., A. Ganopolski, D. Archer, and S. Rahmstorf (2007), Lowering of glacial atmospheric $\mathrm{CO}_{2}$ in response to changes in oceanic circulation and marine biogeochemistry, Paleoceanography, 22, PA4202, doi:10.1029/2006PA001380.

Burke, A., and L. Robinson (2012), The Southern Ocean's role in carbon exchange during the last deglaciation, Science, 335(6068), 557-561, doi:10.1126/science.1208163.

Butzin, M., M. Prange, and G. Lohmann (2012), Readjustment of glacial radiocarbon chronologies by self-consistent three-dimensional ocean circulation modeling, Earth Planet. Sci. Lett., 317, 177-184, doi:10.1016/j.epsl.2011.11.046.

Chen, T., L. F. Robinson, A. Burke, J. Southon, P. Spooner, P. J., Morris, and H. Chin Ng (2015), Synchronous centennial abrupt events in the ocean and atmosphere during the last deglaciation, Science, 349(6255), 1537-41.

Cook, M., and L. Keigwin (2015), Radiocarbon profiles of the NW Pacific from the LGM and deglaciation: Evaluating ventilation metrics and the effect of uncertain surface reservoir ages, Paleoceanography, 30, 174-195, doi:10.1002/2014PA002649.

de la Fuente, M., L. Skinner, E. Calvo, C. Pelejero, and I. Cacho (2015), Increased reservoir ages and poorly ventilated deep waters inferred in the glacial Eastern Equatorial Pacific, Nat. Commun., 6, 7420, doi:10.1038/ncomms8420.

de Pol-Holz, R., L. Keigwin, J. Southon, D. Hebbeln, and M. Mohtadi (2010), No signature of abyssal carbon in intermediate waters off Chile during deglaciation, Nat. Geosci., 3(3), 192-195.

Foldvik, A., T. Gammelsrod, S. Osterhus, E. Fahrbach, G. Rohardt, M. Schröder, K. Nicholls, L. Padman, and R. Woodgate (2004), Ice shelf water overflow and bottom water formation in the southern Weddell Sea, J. Geophys. Res., 109, C02015, doi:10.1029/2003JC002008.

Ganopolski, A., and S. Rahmstorf (2001), Rapid changes of glacial climate simulated in a coupled climate model, Nature, 409(6817), 153-158, doi:10.1038/35051500.

Hain, M. P., D. M. Sigman, and G. H. Haug (2014), Distinct roles of the Southern Ocean and North Atlantic in the deglacial atmospheric radiocarbon decline, Earth Planet. Sci. Lett., 394, 198-208.

Köhler, P., R. Muscheler, and H. Fischer (2006), A model-based interpretation of low-frequency changes in the carbon cycle during the last 120,000 years and its implications for the reconstruction of atmospheric $\Delta^{14}$ C, Geochem. Geophys. Geosyst., 7, Q11N06, doi:10.1029/ 2005GC001228.

Köhler, P., G. Knorr, and E. Bard (2014), Permafrost thawing as a possible source of abrupt carbon release at the onset of the Bølling/Allerød, Nat. Commun., 5, 5520, doi:10.1038/ncomms6520.

Kovaltsov, G. A., A. Mishev, and I. G. Usoskin (2012), A new model of cosmogenic production of radiocarbon ${ }^{14} \mathrm{C}$ in the atmosphere, Earth Planet. Sci. Lett., 337-338, 114-120.

Kusahara, K., H. Hasumi, and G. D. Williams (2011), Impact of the Mertz Glacier Tongue calving on dense water formation and export, Nat. Commun., 2(1), 159-164, doi:10.1038/ncomms1156.

Laj, C., C. Kissel, A. Mazaud, E. Michel, R. Muscheler, and J. Beer (2002), Geomagnetic field intensity, North Atlantic deep water circulation and atmospheric $\Delta^{14} \mathrm{C}$ during the last $50 \mathrm{kyr}$, Earth Planet. Sci. Lett., 200(1-2), 177-190, doi:10.1016/S0012-821X(02)00618-0.

Marcott, S. A., et al. (2014), Centennial-scale changes in the global carbon cycle during the last deglaciation, Nature, 514(7524), 616-619.

Mariotti, V., D. Paillard, D. Roche, N. Bouttes, and L. Bopp (2013), Simulated Last Glacial Maximum $\Delta^{14} C_{a t m}$ and the deep glacial ocean carbon reservoir, Radiocarbon, 55-3(4), 1595-1602.

Monnin, E., A. Indermühle, A. Dällenbach, J. Flückiger, B. Stauffer, T. Stocker, D. Raynaud, and J. Barnola (2001), Atmospheric $\mathrm{CO}_{2}$ concentrations over the last glacial termination, Science, 291(5501), 112-114, doi:10.1126/science.291.5501.112.

Muscheler, R., J. Beer, G. Wagner, C. Laj, C. Kissel, G. Raisbeck, F. Yiou, and P. Kubik (2004), Changes in the carbon cycle during the last deglaciation as indicated by the comparison of ${ }^{10} \mathrm{Be}$ and ${ }^{14} \mathrm{C}$ records, Earth Planet. Sci. Lett., 219(3-4), 325-340, doi:10.1016/S0012-821X (03)00722-2.

Ohshima, K. I., et al. (2013), Antarctic bottom water production by intense sea-ice formation in the Cape Darnley polynya, Nat. Geosci,, 6(3), $235-240$.

Orr, J. C. (2004), Modelling of ocean storage of $\mathrm{CO}_{2}$-The GOSAC study IEA Greenhouse Gas R\&D Programme Rep. PH4/37, 96 p. International Energy Agency. 
Paillard, D., and F. Parrenin (2004), The Antarctic ice-sheet and the triggering of deglaciations, Earth Planet. Sci. Lett., 227, 263-271.

Parrenin, F., V. Masson-Delmotte, P. Köhler, D. Raynaud, D. Paillard, J. Schwander, C. Barbante, A. Landais, A. Wegner, and J. Jouzel (2013), Synchronous change of atmospheric $\mathrm{CO}_{2}$ and Antarctic temperature during the last deglacial warming, Science, 339(6123), 1060-1063, doi:10.1126/science.1226368.

Peltier, W. (2004), Global glacial isostasy and the surface of the ice-age earth: The ICE-5G VM2 model and GRACE, Annu. Rev. Earth Planet. Sci., 32, 111-149, doi:10.1146/annurev.earth.32.082503.144359.

Petoukhov, V., A. Ganopolski, V. Brovkin, M. Claussen, A. Eliseev, C. Kubatzki, and S. Rahmstorf (2000), CLIMBER-2: A climate system model of intermediate complexity, Part I: Model description and performance for present climate, Clim. Dyn., 16(1), 1-17, doi:10.1007/PL00007919.

Reimer, P., et al. (2013), Intcal13 and Marine13 radiocarbon age calibration curves, 0-50,000 years cal BP, Radiocarbon, 52, 1869-1887.

Ritz, S., T. Stocker, and S. Müller (2008), Modeling the effect of abrupt ocean circulation change on marine reservoir age, Earth Planet. Sci. Lett., 268(1), 202-211, doi:10.1016/j.epsl.2008.01.024.

Robinson, L., J. Adkins, L. Keigwin, J. Southon, D. Fernandez, S. Wang, and D. Scheirer (2005), Radiocarbon variability in the western North Atlantic during the last deglaciation, Science, 310(5753), 1469-1473, doi:10.1126/science.1114832.

Singarayer, J., D. Richards, A. Ridgwell, P. Valdes, W. Austin, and J. Beck (2008), An oceanic origin for the increase of atmospheric radiocarbon during the Younger Dryas, Geophys. Res. Lett., 35, L14707, doi:10.1029/2008GL034074.

Skinner, L., S. Fallon, C. Waelbroeck, E. Michel, and S. Barker (2010), Ventilation of the deep Southern Ocean and deglacial $\mathrm{CO}_{2}$ rise, Science, 328(5982), 1147-1151, doi:10.1126/science.1183627.

The Reconstruction of Antarctic Ice Sheet Deglaciation Consortium, et al. (2014), A community-based geological reconstruction of Antarctic Ice Sheet deglaciation since the Last Glacial Maximum, Quat. Sci. Rev., 100, 1-9.

Tschumi, T., F. Joos, M. Gehlen, and C. Heinze (2011), Deep ocean ventilation, carbon isotopes, marine sedimentation and the deglacial $\mathrm{CO}_{2}$ rise, Clim. Past, 7, 771-800 